\title{
Measurement of the temperature profile during evaporation of water and ethanol
}

\author{
Ekaterina G. Korbanova ${ }^{1,2, *}$ \\ ${ }^{1}$ Kutateladze Institute of Thermophysics, 630090 Novosibirsk, Russia \\ ${ }^{2}$ Novosibirsk State University, 630090 Novosibirsk, Russia
}

\begin{abstract}
The temperature profiles across a liquid-gas layers at normal atmospheric conditions are measured for water and ethanol. A thin liquid layer is locally heated from the bottom and evaporates from the liquid-gas interface. Micro-thermocouple with the sensor element thickness of $3 \mu \mathrm{m}$ is used for measurements. It is shown that the temperature profile has a different character for different liquids.
\end{abstract}

\section{Introduction}

Investigations of phase transition phenomena are important for microelectronics cooling applications [1]. The liquid-gas interface is difficult to define for micro-systems, and the effects arising in the Knudsen layer become significant.

The existence of the temperature jump in the Knudsen layer during evaporation has been known in kinetic theory [2,3]. The approach to the description of heat and mass transfer based on the Navier-Stokes equations with temperature and pressure jumps conditions at liquid-vapor system was suggested in [4]. Analysis showed a good agreement with the temperature and pressure profiles calculated basing on the Boltzmann kinetic equations. However, most of the experimental data on the temperatures jumps at the liquidgas interface were available only for reduced pressure conditions [5,6]. Recently, authors of $[7,8]$ performed precise experiments on the temperature jump measurements using microthermocouple with the sensor thickness of $3 \mu \mathrm{m}$ for normal atmospheric conditions. A temperature jump at the liquid-gas interface has been clearly detected even for small evaporation rate and the temperature jump value is found to increase with increasing the temperature difference between heater and ambient gas [8].

\section{Experimental setup}

Results of an experimental investigation of the temperature field of liquid-gas layers are presented. Experiments are carried out for two types of liquids at local heating and evaporation. Ultrapure Water (MilliQ) and 99\% ethanol are used as working fluid for experiments. The experiments are performed at quasi-stationary heating mode. The temperature of the heater is controlled by three thermocouples. The humidity and

* Corresponding author: korbanova20@gmail.com 
temperature of the ambient air inside the box are monitored by Testo device. The pressure is measured by barometer. The temperature profiles across the liquid-gas interface are measured using the specially fabricated micro-thermocouple with the sensor thickness of less than $3 \mu \mathrm{m}$ (Fig. 1). The experimental setup presented in [8] is used.

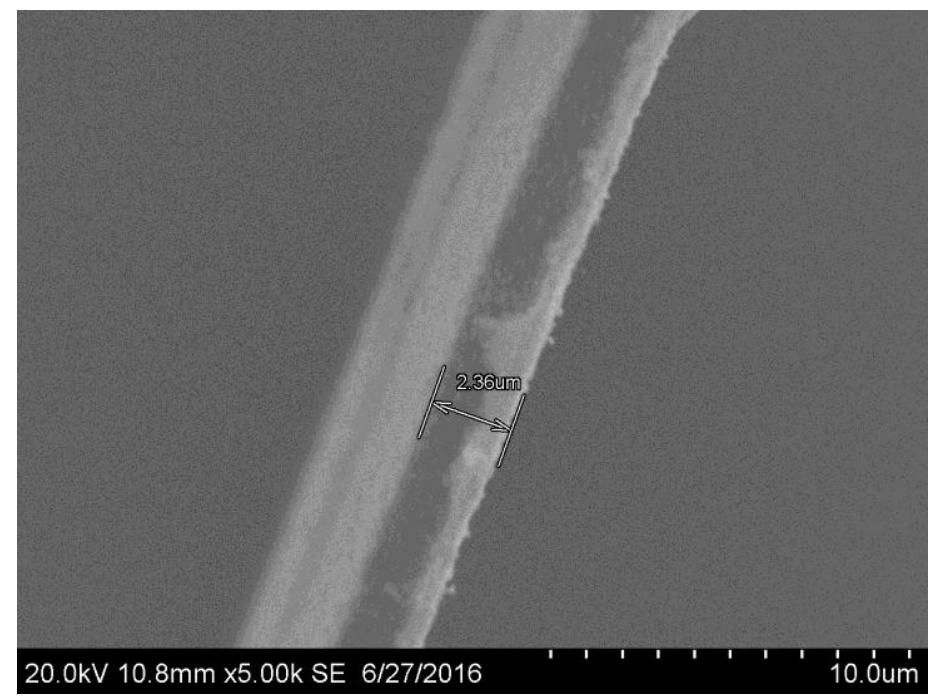

Fig. 1. SEM image of micro-thermocouple by Hitachi S340.

Calibrations of all thermocouples are carried out in the temperature range $5-100{ }^{\circ} \mathrm{C}$. Two reference thermometers, ETS-100, are used. Each one has uncertainty of $0.02{ }^{\circ} \mathrm{C}$ in the tested temperature range. Calibration is performed using calibrator KS-100-1. Data registration is carried out by means of temperature control and measurement system consisting of data collection (NI 9214) and the corresponding software. The precise miniature motorized linear stage (Zaber), used as micro-positioner. It displaces the microthermocouple and determines its position. The range of the micro-positioner' movement is $25 \mathrm{~mm}$ with the minimal step of $0.05 \mu \mathrm{m}$. The micro-positioner is connected to a personal computer and it is controlled by specially developed software. The shadow technique is used for visualization with video camera providing a resolution of $3 \mu \mathrm{m}$ per pixel.

\section{Results}

Synchronization of the micro-thermocouple readings and its position via time is made by specially developed software. The measurements allow us to obtain detailed information on the temperature profile across the liquid-gas layers. The existence of the temperature jump at the liquid-gas interface at atmospheric conditions has been established in [8] for water-air system. Fig. 2a shows the temperature profile for water-air system. The temperature jump is clearly indicated. Fig. 2 b presents the temperature profile for ethanolair system. One can see a different temperature curves for water and ethanol. The evaporated liquid flow rate is measured to be of $0.215 \mu \mathrm{l} / \mathrm{s}$ for water - air system at the heating power of $1.07 \mathrm{~W}$. 


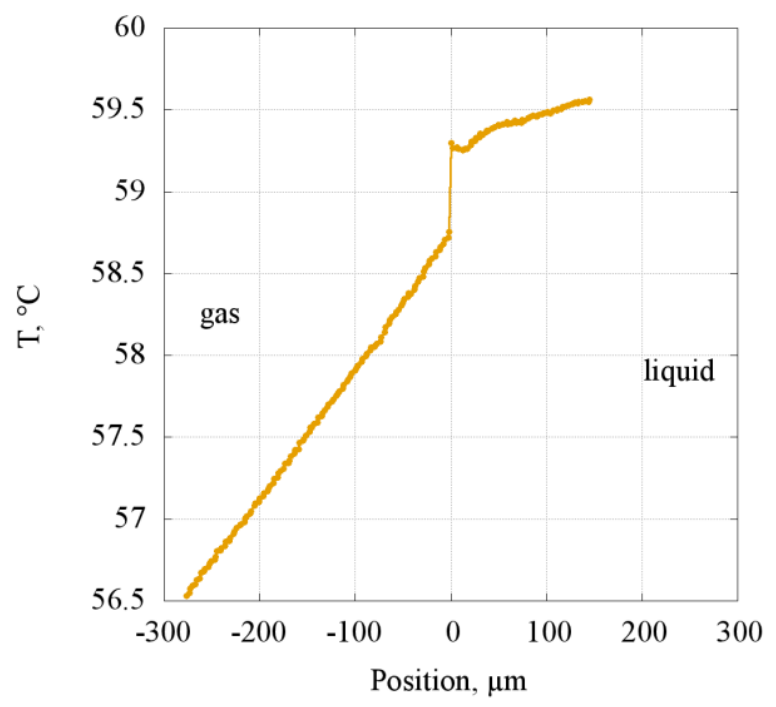

a

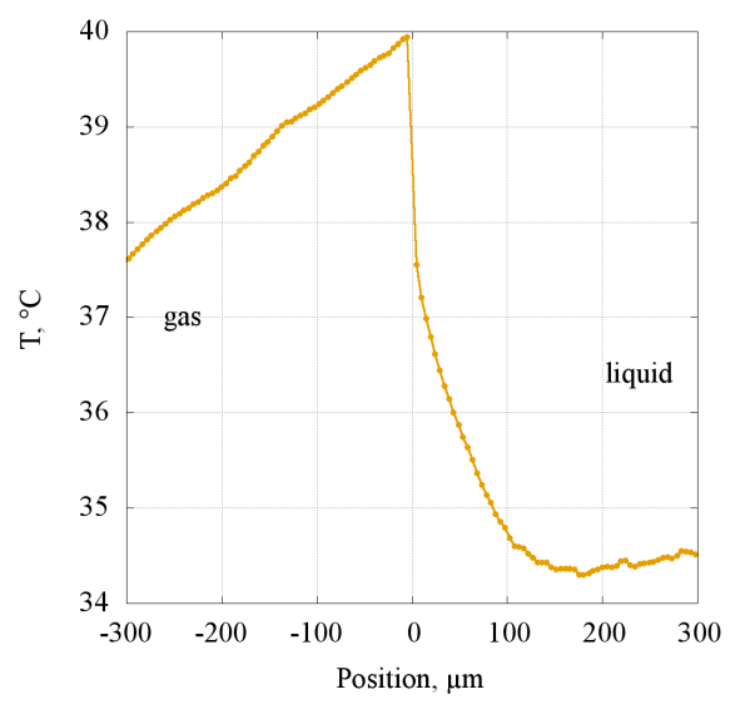

b

Fig. 2. Temperature profile: $a$ - for air - water system, heating power is $1.07 \mathrm{~W}$, average temperature of the heater is $88.2{ }^{\circ} \mathrm{C}$, air temperature is $32.3^{\circ} \mathrm{C}$, air humidity is $30.2 \%$, pressure is $99.46 \mathrm{kPa} ; b-$ air - ethanol system, heating power is $1.11 \mathrm{~W}$, average temperature of the heater is $84.7{ }^{\circ} \mathrm{C}$, air temperature is $24^{\circ} \mathrm{C}$, air humidity $42.5 \%$, pressure is equal to $99.59 \mathrm{kPa}$.

\section{Conclusions}

The temperature profiles across a liquid - gas layers are measured at normal atmospheric conditions for water and ethanol. A thin liquid layer is locally heated from the bottom 
substrate and it evaporates from the liquid-gas interface. Micro-thermocouple with the sensor element thickness of $3 \mu \mathrm{m}$ is used for measurements. It is shown that the temperature profile may have a different character for water and ethanol. The evaporated liquid flow rate is measured to be of $0.215 \mu \mathrm{l} / \mathrm{s}$ for water - air system at the heating power of $1.07 \mathrm{~W}$.

The authors gratefully acknowledge the support of this work by the Ministry of Education and Science of the Russian Federation (Agreement 14.616.21.0016, project identifier RFMEFI61614X0016).

\section{References}

1. O.A. Kabov, E.Ya. Gatapova, D.V. Zaitsev, Thermal and Thermomechanical Phenomena in Electronic Systems, 2008. ITHERM 2008. 11th Intersociety Conference on, 520 (2008)

2. Y.P. Pao, Phys. Fluids 14, 1340 (1971)

3. R.Ya. Kucherov, L.E. Rikenglaz, J. Exp. Theor. Phys.+ 37, 88 (1960)

4. E.Y. Gatapova, I.A. Graur, F. Sharipov, O.A. Kabov, Int. J. Heat Mass Tran. 83, 235 (2015)

5. P.N. Shankar, M.D. Deshpande, Phys. Fluids A 2, 1030 (1990)

6. G. Fang, C.A. Ward, Phys. Rev. E 59, 417 (1999)

7. E.Y. Gatapova, R.A. Filipenko, Y.V. Lyulin, I.A. Graur, I.V. Marchuk, O.A. Kabov, Thermophys. Aeromech. 22, 701 (2015)

8. E.Y. Gatapova, I.A. Graur, O.A. Kabov, V.M. Aniskin, M.A. Filipenko, F. Sharipov, L. Tadrist, Int. J. Heat Mass Tran. 104, 800 (2017) 